\title{
Study on the methods and modes of modern English Teaching
}

\author{
Zhao Hui Min ${ }^{1, \text { a }}$ \\ ${ }^{1}$ Bohai university, Jinzhou, 121013 China \\ ahmzhao2008@163.com
}

Keywords: Modern English; teaching methods; modern means; computer assisted instruction; communicative approach.

\begin{abstract}
With the rapid development of information technology, multimedia technology has been widely used in modern education. In English teaching, one can take the advantages of modern educational technology, to accommodate a variety of English teaching methods. Teachers display the courseware using video and audio system, and attract students to participate in learning. In this article, the author discusses the advantages of English teaching via modern technology and its application in English teaching.
\end{abstract}

\section{Introduction}

With the high tide of economic globalization, with the deepening of teaching reform and the development of science and technology, multimedia technology is becoming a necessary auxiliary means of English teaching. Multimedia can express more information, so that information can be extended from single visual information to visual, auditory and other media information. The computer multimedia technology into the field of education, the development of multimedia courseware, to provide the most convenient conditions toward the map, text, sound, scene and traditional teaching direction, it makes the teaching of image thinking and abstract thinking complement each other, complement each other, complement each other, is an important form of teaching to a higher level of development. This will have a profound impact on teaching practice and theory research field. In recent years, multimedia computer assisted instruction has become more and more widely used in the field of modern education. The use of computer, television, radio, and video, VCD, DVD, slides, projectors and other multimedia teaching has become an important means in foreign language teaching. Teachers can according to the development of multimedia courseware for classroom teaching needs, timely adjust and reform the teaching content, enriching teaching methods, improve teaching efficiency and quality[1], promote the teaching research, and constantly improve the students' listening ability, for the social transmission of more qualified foreign language compound talent. In a word, the master and the use of multimedia computer, and make full use of multimedia teaching methods for educational services will become an important condition for the information age in twenty-first Century to measure a qualified educator.

In the process of English teaching, especially the students to learn the new language by hearing materials used in the introduction of new courses, through natural communication show new language materials, creating scenarios for students to carry out classroom communicative activities. While English needs a lot of language environment, many words, the best information processing multimedia naturally becomes. If you can give full play to the advantages of modern educational technology, to accommodate a variety of conventional teaching methods of long, let the teacher according to the teaching requirements, can through simple operation to the disk, disk image, animation, spelling, writing, application of language teaching carrier of information transfer at any time, the circulation in different interface, and display on the students have used video and audio system, to attract students to participate in learning. And teachers can accord the learning needs and learning status, transmission density and transmission speed of arbitrary control of teaching information, select and expand any channel information at any time, learning efficiency and quality feedback, so English teaching will be carried out in the multimedia environment, colorful graphic illustrations, vivid and interesting. The students from passive to active to strive for, thus more quickly 
and more effectively to complete teaching tasks, and comprehensively improve the quality of English teaching.

\section{The traditional way of education and audio-visual education means to infiltrate each other}

\section{Modern listening equipment.}

Listening, speaking, and reading, writing and translating are the five skills of foreign language learning. The importance and difficulty of listening to the first one is the importance and difficulty of listening. "Listening" plays a very important role in English learning and all kinds of examinations. However, a considerable part of the students' hearing is weak, poor listening ability, "fear" and "headache" hearing. Due to the reasons, students have some problems in basic skills, pronunciation, grammar and vocabulary. Some students often say: a very simple sentence is easy to read, but it sounds like a response, do not understand. Try to analyze, because listening is fleeting, don't remember; two is because the rules and skills of listeners in listening materials, phoneme blasting liaison, stress, weakening, assimilation, voiced consonants, and the rhythm of the three is not familiar with, because listening equipment simple, single method. The only sound audible, it is difficult for students to correctly understand the accurate information expressed in listening materials. Listening is a receptive skill, but listening comprehension is a comprehensive test of listening, reading, comprehension and memory. It requires the students to understand the language material, the use of language knowledge, such as pronunciation, semantics, syntax, and use of non linguistic knowledge, such as cultural background, knowledge, speculation and judge the correct answer; listening fleeting characteristics also require students to have certain memory ability. Listening tests have been a challenging project for non English speaking countries. The use of audio-visual media creates problems, stimulate students' interest in learning English, play the main role of the students. However, integrated use of multimedia language laboratory provides a broad space for imagination and analog tape recorders, DVD, video, voice room, projectors, projector, TV, computer etc. This audio-visual equipment for English teaching, so that students can be limited within forty-five minutes, to grasp more knowledge. Because the operation is simple, easy to control, and can achieve results [2].

\section{To create a good learning atmosphere.}

Can create a good learning atmosphere for students. So that the problem can be a good solution, the use of audio and visual media, the use of sound, form, color as a whole, making teaching more intuitive, more vivid. To cultivate the students' interest in learning a foreign language, initiative and self-consciousness, broaden their horizons, to broaden the knowledge and expand their vocabulary, and to make students get all-round training and improvement in basic language knowledge. Make the classroom atmosphere lively, vivid, impressive, this is where the beauty of audio-visual teaching. Psychologists have studied this morning. The study of modern psychology indicates that various human organs is very large in the acceptance of difference information in the role, which is the strongest visual information, accounting for $60 \%$ of the total, accounting for $20 \%$ of the auditory, tactile taste accounted for $15 \%$, accounting for $3 \%$, accounting for $2 \%$ of the sense of smell. From the effect of memory, the information obtained through different ways, over a period of time is not the same rate of memory. If you use only hearing, three days after the memory rate of $10 \%$; the use of visual, three days after the memory rate of $20 \%$; auditory and visual and used, three days after the memory of up to $65 \%$. The above results prompted us to reform the listening class will try, the previous simple information through sound listening teaching reform of audio-visual teaching through the audio-visual information, to enlarge the students' access to information channels, improve teaching efficiency and cultivate students' innovation ability. The use of CAI (Computer Assistant Instruction) modern education technology to a large number of abstract letter symbols through the preferred figure, sound, language environment fully embodies the language features. The CAI disc is crystal creative experts for decade's English teaching experience, and gets a lot of teachers' guidance, according to a text of each function, structure and key points and difficulties, the students as learning reference materials, teaching errors caused by many factors in the teaching 
process to avoid. CAI teaching better follows the students' cognitive law. The function of image, sound and language environment in students' cognitive activities is fully reflected. CAI teaching technology to make teaching methods tend to all-round, multi-level, with a vivid image of the teaching content, interesting, fascinating. Multimedia teaching applied in the classroom teaching, not only can achieve the interaction between students and the machine, but also to achieve the students and students, between students and teachers to communicate with each other. Because it is possible to do human computer interaction, and a positive teaching atmosphere is the key to a good lesson. CAI teaching in the feedback information control and learning exchange, more than other means have obvious advantages. For example in teaching dialogue scene, through the voice of speech, teaching demonstration, die - A and B are respectively simulated demonstration of dialogue, the other half of this dialogue is simulated by the computer to complete the speech, vivid, and create a successful learning environment for language learning[3].

\section{Application of CAI teaching structure.}

CAI also can optimize the structure of classroom teaching. In a class based teaching demonstration, speech dialogue function, teachers can explain the presentation, students can timely feedback; by answering questions, so many aspects into an organic whole, optimize the structure of classroom teaching, improve teaching quality. CAI has the advantages of easy operation, running game, interactive and so on, which greatly improves the degree of students' participation in learning. If students can use the mouse to complete the exercise, can be used independently of the disc, for any language point of learning or review, to facilitate the teaching of teachers, more convenient for students to learn. CAI can greatly stimulate the students, especially the students with learning difficulties in learning English. On the one hand, the screen on the screen gorgeous color, lovely cartoon image, the magic of animation and other effective to attract the attention of students, to arouse the attention of all the students. On the other hand, the students through the computer to complete the task of learning, curiosity and a sense of achievement have been greatly satisfied. On the other hand, the sound of the voice and background music to render a very relaxed and pleasant learning atmosphere, so that students naturally immersed in the joy of learning. Four, the use of multimedia courseware, help to cultivate students' divergent thinking and language expression ability, to strengthen the classroom intuitive effect, promote the improvement of English thinking ability. The multimedia courseware provides images, animation, video and other graphic audio and activity situation instead of static picture text, more easily arouse the interest of students, so it is helpful to cultivate students' ability to observe things, is also easier to stimulate and cultivate students' imagination. The use of multimedia software friendly interface and multimedia hypertext structure, the actual situation of teachers to students, from the outside to the inside, from the shallower to the deeper, according to from individual to general, from the concrete to the abstract knowledge of, using a different way, effectively guide the students to observe, to improve the students' ability to observe, analyze things. For example: the slide cover made of type, change the contents of a slide show, one by one step of teaching content. Educator Zukav once pointed out: only know how to impart knowledge; do not know how to develop students thinking ability of teachers are not complete teachers. Therefore, the use of slides and other multimedia teaching, to help students to master a large number of rich content, profound perceptual knowledge, which is essential to strengthen the students' abstract logical thinking. To this end, we focus on the development and use of educational technology. Multimedia Assisted English teaching provides students with an excellent environment for individual counseling. Teaching on condition of class differences, English level and ability of the students is the objective existence, solve the difficult teaching, multimedia into the classroom, will be able to provide the necessary material conditions and different levels of students, so that students in the same learning time, have different learning state, have their own play world[4]. 


\section{Effective comprehensive utilization of multimedia language laboratory}

\section{Comprehensive utilization of voice laboratory.}

The computer, TV, radio, video, VCD, DVD, slide projector, comprehensive utilization of the multimedia teaching process cannot do without the language laboratory. Language laboratory is the best place for language practice, and it plays a very important role in improving the quality of foreign language teaching. Advanced audio-visual equipment for our various forms of organization that provides a convenient classroom teaching, so that teachers can use a variety of means, many aspects of training the students. Students not only see the class, ears, mouth, but also actively thinking about the brain, so that the ability to strengthen the training of training. In the process of multimedia teaching, if the audio-visual and audio-visual equipment is the key to success in the teaching of language laboratory, then the leading role of teachers is the key to the core, because the audio data collection, compilation and use of the appropriateness of understanding and application of the technical performance of audio-visual equipment, depends entirely on my teachers, those just think of language lab press pressing button, playing the tape, look at the video idea, while it can be said for the teaching of irresponsible, light at least can be said that the lack of understanding of listening and speaking, language laboratory. In fact, for the use of language laboratory teachers, the requirements are very high, in addition to the requirements of the business, but also to understand the various functions of language laboratory, to master its operation and use. Teachers also need to spend a lot of time on the preparation of material selection, editing, printing handouts, ready to sound data - such as audio tapes, video tapes, and the design of classroom teaching procedures. When teaching, more attention should be paid to individualized, targeted, step by step, from the shallower to the deeper, a lot of training, because listening and speaking skills must be formed through continuous practice to achieve power setting (dynamic type). In the specific and clear objectives of the stimulus, through a number of times in the specified period of time and a lot of intensive training, the formation of skills can be guaranteed. In a word, the rapid improvement of listening and speaking ability depends on a large number of practice and strict training in the language laboratory. Language lab is the best venue for language practice. We use the language laboratory in the teaching of listening and speaking of two types of contrast and audio-visual. The so-called AUDIO-ACTIVE language laboratory (Language Laboratory), mainly by a teacher to manipulate the central console and a number of Taiwan students use the dual channel tape recorder. Each student can listen to the teacher's speech and listen to the tape from the console and record them on their tape. The students through the microphone can record your voice. In this way, he can listen to the teacher and his own recordings. The teacher can practice at any time listening to a student in the center console, and talk to him so as not to affect other people, which is conducive to improve the enthusiasm and initiative of students, cultivate their learning ability of independent practice speech. Language (audio-visual laboratory) is a kind of language laboratory which uses audio-visual teaching material to carry on the teaching. In addition to the AUDIO-ACTIVE language laboratory (Language Laboratory) function, but also to show the picture, students can listen, but also to see, as, listening, speaking and teaching and training. Through years of teaching practice, we deeply feel that the multimedia language lab provides modern teaching means for listening and speaking, is an ideal place for students to master the language; the media language laboratory provides a rare condition for multimedia teaching and oral English test. It has played a positive role in teaching reform and improving the quality of foreign language teaching.

\section{Using multimedia teaching to increase the capacity of the classroom.}

In English teaching, the teaching time is very limited; the use of multimedia courseware for teaching can save a lot of time in classroom teaching, increase the capacity of the classroom. We can use the courseware for words or phrases flash, image scaling and moving, color transformation, etc. According to the law of easy to difficult, the use of the design of good software to send a number of exercises, such as time saving, and easy to operate. The teacher writing on the blackboard, drawing, save a lot of time to produce exercises, can focus on how to play the leading role, how to inspire the students' thinking, makes forty-five minutes to get a more reasonable use. As in the teaching of the 
comparison and the most senior, can play an animation: a red ball and a green big ball. The teacher asked: "which is bigger, the red ball or the green one?" at the same time the sentence displayed and bigger is red and bold, students will answer "The green ball" by common consent at the same time the teacher will answer on the screen, and then click the mouse a big blue ball to jump out, the teacher asked "which is the biggest of the three?" the biggest also showed a sentence and bold red. With the student's answer, the answer "The blue one after is the biggest. on" let the students do something similar from easy to difficult questions, and answers to the problems in different ways, not only save a lot of time on the blackboard, and stimulate students' interest in learning, improve students' learning effect. Large capacity and different levels of exercise and the various levels of the students are able to fully consolidate, avoid the gifted students do not have enough, do not have enough to eat in the situation, make the students interesting easily completed a lesson learning task[5].

\section{Summary}

The application of multimedia computer assisted instruction in the field of modern education in the increasingly widespread, enrich the traditional teaching method, reform the way of information transmission, change people's ideas and concepts, reform the traditional teaching mode, improve the teaching level, in the conventional way of teaching has played a positive role. At present, domestic universities have to use modern media teaching, audio-visual education leading to the traditional education as the foundation, the close combination of the two, the traditional way of education and educational means mutual penetration of traditional text materials complement each other with audiovisual materials, play their respective advantages, improve teaching quality, bring new the weather for the education reform. Can assert, master and use of multimedia computer, multimedia computer assisted instruction with appropriate means for educational services will become one of the important conditions of information age in the twenty-first Century to measure a qualified educator. In the future, we will continue to work hard in the field of foreign language teaching, especially the comprehensive utilization of a variety of educational media and optimization combination, constantly explore and make contributions to the further development of China's foreign language teaching career.

\section{Acknowledgements}

This work is supported by Social Science Foundation of Liaoning Province (No. L15DWW005) and Bohai University Teaching Reform Project (No.BDJG15QNB002).

\section{References}

[1] Wang Wang. The application of task based approach in English reading of higher vocational education [J]. contemporary educational practice and teaching research. 2016 (08).

[2] Liu Ruiqiong. The application of project teaching method in English Teaching of secondary vocational school [J]. education modernization. 2016 (13).

[3] Tian Feng. Discussion on how to construct the junior high school English efficient class [J]. Chinese school education. 2016 (19).

[4] Bai Li. A study of English Teaching in light and shadow -- teaching method and design of the advanced English listening and speaking teaching method and design [J]. exam week 2016 (64).

[5] Xie Zhijiang junior high school English teaching methods to explore the [J]. exam week. 2016 (64). 